\title{
FISCAL POLICY EFFECTIVENESS AND RISKS IN THE DEVELOPMENT OF AZERBAIJAN'S ECONOMY DURING ECONOMIC SHOCK
}

\author{
Shafa Guliyeva \\ Azerbaijan State University of Economics (UNEC), Baku, Azerbaijan
}

Nushaba Gadimli

Mingachevir State University, Mingachevir, Azerbaijan

Yalchin Azizov

The Institute of Economics of Azerbaijan National Academy of Sciences, Baku, Azerbaijan

\section{Zaur Hajiyev}

The Institute of Economics of Azerbaijan National Academy of Sciences, Baku, Azerbaijan

\section{Sanan Bayramov}

Azerbaijan State University of Economics (UNEC), Baku, Azerbaijan

\begin{abstract}
The purpose of this study is to empirically evaluate the effectiveness of fiscal policy in the context of the economic slowdown in Azerbaijan caused by the COVID-19 pandemic. Using the Granger test, causal relationships between fiscal indicators and indicators of macroeconomic development in Azerbaijan have been determined. Based on an oriented graph, the hierarchy levels of indicators of fiscal policy and economic development effectiveness have been substantiated. An integrated assessment of the development of the national economy under the influence of the fiscal policy in the country is presented. Using regression analysis, fiscal risks have been identified that have a destabilizing effect on the economy and aggravate its state during a period of economic shock in the short term. A hypothesis about the different influence of the values of the public expenditure multipliers on the economy, depending on their functional directions, has been confirmed. The structure of expenses of the state budget of Azerbaijan has been empirically optimized, increasing production expenses. The results obtained can serve as a basis for enhancing the anti-crisis strategy of the fiscal policy of the past, not only in a crisis but also to ensure the sustainability of economic development.
\end{abstract}

Keywords: fiscal policy, fiscal risks, economy, Azerbaijan, economic shock, COVID19 pandemic.

DOI: http://dx.doi.org/10.15549/jeecar.v8i2.710 


\section{INTRODUCTION}

A feature of the socio-economic development of Azerbaijan in modern conditions, as in all countries of the world, is the detrimental effects anti-crisis measures to contain the spread of the COVID-19 pandemic have had on its economy. Containment measures and social distancing provoked a drop in the country's 2020 GDP in by almost $4.3 \%$, causing the national economy's deepest recession over the past 25 years (OECD, 2020). The government and the Central Bank of Azerbaijan have introduced a wide range of fiscal and liquidity support measures to counter the economic impact of the pandemic. Discretionary fiscal policy is mainly aimed at increasing health care spending in 2020 by $0.5 \%$ of GDP (Ministry of Finance Republic of Azerbaijan, 2021), and the Public Health COVID-19 Response Fund was established with AZN 116 million (0.14\% of GDP) (Ministry of Finance Republic of Azerbaijan, 2021). The immediate political response of the Government of Azerbaijan was also focused on supporting the most economically vulnerable and providing AZN 3.3 billion (4.85\% of GDP) in liquidity to economic entities of (Ministry of Finance Republic of Azerbaijan, 2021). Also, amendments to the Tax Code were promptly instituted, providing tax incentives to businesses affected by the COVID-19 pandemic in the amount of $0.2 \%$ of GDP (Ministry of Finance Republic of Azerbaijan, 2021).

In the context of the coronavirus pandemic, the government was forced to increase government spending to $42.3 \%$ of GDP in 2020 , and an increase was planned for 2021 by $3.8 \%$ from the previous year (OECD, 2020a). But amid an increase in budget spending and a fall in the economy, there is additional pressure caused by the resumption of the military conflict with Armenia at the end of 2020 and a new OPEC+ deal, within the framework of which Azerbaijan was forced to cut oil production amid a rapid drop in oil prices (The Ministry of Energy of the Republic of Azerbaijan). This, in turn, generates current fiscal risks to the national economy, namely: an increase in inflation; an increase in the state budget deficit and debt' a decrease in the profitability of the banking system; an increase in corporate debt, etc. Fiscal risks threaten the country's creditworthiness, increase pressure on the cost of borrowed capital, and form the preconditions for an uncontrolled rise in inflation (OECD, 2020b). Intending to overcome these vulnerabilities, it is fundamentally essential to apply macroprudential policy measures to avoid risks to economic growth in the medium term.

The most accurate identification and analysis of fiscal risks and the effectiveness of fiscal policies can form the basis for developing an anti-crisis fiscal strategy capable of adequately responding to many future budgetary shocks in the national economy. This makes it possible to reduce the scale of the destructive impact on the fiscal balance and the economy, which is especially important in a difficult situation such as a pandemic and its consequences. Therefore, within the framework of this study, the analysis of the fiscal policy of Azerbaijan in the conditions of an economic shock was carried out by assessing the multiplier effect of the dynamics and structure of budget expenditures on the country's economic development. The main fiscal risks and the level of their destructive impact on the national economy in the context of the COVID-19 pandemic have been identified.

\section{LITERATURE REVIEW}

As the experience of previous economic shocks and fiscal risk management shows, discretionary fiscal policy appears to be the most effective instrument of state regulation of the economy (Montes \& de Hollanda Lima, 2021). The goal, which in the short term is to smooth out cyclical fluctuations and stabilize the economy; that is, to maintain a stable GDP volume, full employment of resources, a stable price level, etc. by deliberately manipulating the level of taxation in the country and the volume of government spending (Larch et al., 2021). The structure of specific measures depends on the government's goals and the ratio of the effectiveness of implementing these measures on the part of revenues and budget expenditures (Larch et al., 2021; Vinhado \& Divino, 2019).

Modern economic literature examines fiscal risks and the effectiveness of the fiscal policy, as a rule, in the face of a shock to aggregate demand (financial crises, reduced investment inflows, excessive export dependence) (Montes \& de Hollanda Lima, 2021; Larch et al., 2021; Vinhado \& Divino, 2019). Or in a crisis of aggregate supply 
(volatility in the level of prices for crude oil, a decrease in labor productivity and the quality of human capital, etc.) caused by the transformation of the behavior of the private sector or as a result of unpredictable natural incidents (Yasmin, El Refae \& Eletter, 2020; Jin \& Xiong, 2021; Gross, 2020). But if we consider the current situation, the generation of fiscal risks (growth of the budget deficit, public debt, etc.) occurs in the context of a shock to both market consumption and market demand., both of which were caused by deliberate government action in fiscal response to COVID-19 pandemic risks (Makin \& Layton, 2021; Megits, Neskorodieva \& Schuster, 2020). Analysis of the scientific literature has shown that today's scientists do not analyze the effectiveness of fiscal policy and fiscal shocks associated with the humanitarian crisis of the health care system, which arose as a result of the government's deliberate blocking of national borders on a global scale, disruption of supply chains and changes in household behavior (Makin \& Layton, 2021; Edelberg \& Sheiner, 2020) and can be compared the current situation with similar studies of economic shocks and the effectiveness of public administration during wartime. (Brown, 2019).

A wide range of scientific research is characterized by a scientific discussion on economically feasible volumes for the corresponding level of development of the country and the optimal structure of public spending both in general and in individual functional sections and articles (Bouakez, Guillard \& Roulleau-Pasdeloup, 2020; Hu \& Lei, 2017). The available empirical studies reliably indicate only the presence of a certain level of government spending as a percent of GDP, before which their increase contributes to economic growth, and, if exceeded, negatively affects economic development (Malcolm, 2017; Divino, Maciel \& Sosa, 2017). According to many economists, going beyond these optimal limits in the existing institutional conditions will not stimulate economic growth. This level can vary significantly for developing and developed countries (Bouakez, Guillard \& RoulleauPasdeloup, 2020). In the pre-pandemic period, developing countries, especially in Asia, were characterized by faster rates of economic development, especially in the period after the crisis of 2008-2010 (United Nations, 2015). This means that fiscal risks and economic shock will have a more destructive and profound impact on the economy. Therefore, within the framework of this study, an attempt is made to answer the question of how effective modern fiscal policy is on the example of Azerbaijan, how extensive and timely the measures were, what fiscal risks currently accompany the national economy, and what measures should be taken to support economic entities and minimize risks caused by the COVID-19 pandemic.

\section{METHODOLOGY}

The first stage of the study was the formation of indicators characterizing the effectiveness of the fiscal policy, based on the IMF methodology for assessing fiscal risks (International Monetary Fund, 2016), as well as scientific publications (Makin \& Layton, 2021; Hu \& Lei, 2017; Bouakez, Guillard \& Roulleau-Pasdeloup, 2020) and indicators of macroeconomic development in Azerbaijan (Ari \& Koc, 2020; Soreg \& BermudezGonzalez, 2021).

The list of indicators for assessing the effectiveness of fiscal policy and macroeconomic development of the country is as follows:

Fiscal Policy Performance Indicators:

- Bal - The state budget balance to GDP growth rate, \%;

- Rev.GR - State budget revenue growth rate, $\%$;

- Ex.GR - State budget expenditures growth rate, \%;

- Tax.GR - Tax revenue growth rate, \%;

- Var - The level of variability of state budget revenues, \%;

- ExEC - Specific weight of productive expenditures (power expenditures) in the structure of state budget expenditures, \%;

- ECOSOC - Specific weight of expenditures on social protection and social security in the structure of state budget expenditures, \%;

- ExED - Specific weight of expenditures on education in the structure of state budget expenditures, \%; 
- ExH - Specific weight of expenditures on health care in the structure of state budget expenditures, \%;

- ExC - Specific weight of expenditures on activities in the field of culture, art, information, physical education in the structure of state budget expenditures, \%;

- ECSC - Specific weight of expenditures on science in the structure of state budget expenditures,\%;

- ExJ - Specific weight of the costs of the judiciary, law enforcement agencies, and the prosecutor's office in the structure of state budget expenditures, \%;

- ExLEG - Specific weight of expenditures for the provision of legislative and executive power, local government bodies in the structure of state budget expenditures, \%;

- ExD / GDP - Cost of public debt service-toGDP ratio, \%;

- ExD / REV - Cost of public debt service -tostate budget revenues ratio, \%;

- D / GDP - Debt-to-GDP ratio, \%;

- D.E / GDP - External debt-to-GDP ratio, \%;

- D.E / EXP - External debt-to-volume of exports of goods and services ratio, \%;

- D.GR - Public debt growth index (internal and external), \%;

- D.E.GR - External debt growth rate, \%;

- Pl.Rev - Percentage of implementation of the plan for state budget revenues,\%;

- Pl.Ex - Percentage of implementation of the plan for state budget expenditures,\%;

Indicators of macroeconomic development:

- GDP - GDP per capita growth rate, \%;

- Inc - Population income growth rate, \%;

- Unemp - Unemployment rate, \%;

- IP - Industrial Production growth rate, \%;

- As - Value of fixed assets growth rate, \%;

- Depos - Household deposits growth rate, \%;

- Wag - Average monthly nominal wages growth rate, \%;

- EAP - Economically active population growth rate, \%;
- Inv - Investments to economic growth rate, $\%$;

- Cur - Devaluation level of the national currency, \%;

- Trade - Index of retail trade, public catering, and paid services to the population, \%;

- Pr.Ind - Producer price index for industrial products,\%;

- Pr.Cons - Consumer Price Index,\%;

- Imp - Volumes of imports of goods and services growth rate, \%;

- Exp - Volume of exports of goods and services growth rate,\%;

- Pov - Poverty rate, \%;

- Pen - Nominal average pension growth rate, $\%$.

To determine the mutual influence between the indicators, the Granger test was used, which helped determined statistically significant chains of cause-and-effect relationships. The use of the Granger test was possible due to the stationarity of the time series of indicators, confirmed by the augmented Dickey-Fuller method. The check of indicators for stationarity and causality of relationships was carried out based on annual values of indicators for Azerbaijan for the period 1991-2020 (The State Statistical Committee of the Republic of Azerbaijan, 2021; Ministry of Finance Republic of Azerbaijan, 2021) using the EViews 10.0 program. The Granger test with a time lag of 1-4 periods (years) and without a time lag made it possible to establish some causal relationships between indicators characterizing fiscal policy and indicators of macroeconomic development.

The cyclical nature of the relationship between some indicators, revealed by the results of the Granger test, and the absence of a single resulting indicator reflecting the influence of all the others, necessitated the use of the graph method. With its help, the structuring of indicators of the effectiveness of fiscal policy and macroeconomic development of Azerbaijan by levels of hierarchy was carried out. The highlighted levels have been formed with the indicators of fiscal policy that affect the country's macroeconomic development and characterize fiscal risks (1st level of the hierarchy), and the resulting 
indicators reflected this influence (upper level of the hierarchy).

To influence the parameters of fiscal policy based on the values of the indicators that formed the highest level of the hierarchy, the integral indicator of the macroeconomic development of Azerbaijan was calculated by the method of additive convolution based on the normalized values of the indicators, adjusted for the coefficients of significance:

$$
\begin{gathered}
I=\sum_{i=1}^{n} X^{\prime} \times \frac{d_{i}}{\sum d_{i}} \\
X^{\prime}=\frac{X-X_{\min }}{X_{\max }-X_{\min }} \\
X^{\prime}=\frac{X_{\max }-X}{X_{\max }-X_{\min }}
\end{gathered}
$$

Where:

$X$ is the actual value of indicators;

$X$ 'is the normalized values of indicators.

For stimulating indicators, the growth of which testifies to the economic development of the country, formula (2) was used for rationing, formula (3) was used with stimulating indicators;

$$
\begin{aligned}
& d i \text { - the variance of the } i \text {-th indicator; } \\
& n \text { - the number of indicators. }
\end{aligned}
$$

The principal component method in the Statistica 12.0 program was used o calculate the significance coefficients. Significance coefficients correspond to the percentage of the factor variance. The factors are formed in such a way that one indicator corresponds to each factor. At the same time, the primary function of factor analysis - data reduction - is not performed. Still, the calculated values of the percent of variance can be interpreted as the coefficients of the significance of each particular indicator, each of which formed a separate factor.

The values of the integral indicator of the economic development of Azerbaijan, calculated according to formula (1), were used as a dependent variable in modeling the impact of fiscal policy parameters on the country's macroeconomic development and identifying fiscal risks using regression analysis in the Statistica 12.0 program.

\section{RESULTS}

In Figure 1, causal relationships are shown that are significant at a significance level of 0.05 , the aggregate of which represents an oriented graph of relationships between indicators of the effectiveness of fiscal policy and the economic development of Azerbaijan. The constructed graph helps to indicate how the main indicators of fiscal policy are reflected in the investments growth ratio into the economy (internal and external), the level of devaluation of the national currency, the index of consumer prices, and prices for industrial products, the real average monthly pension, and wages growth ratio, the household deposits growth ratio, the value of fixed assets growth ratio, the index of industrial production, the unemployment rate, the exports and imports growth ratio. In most cases, this leads to a change in GDP per capita and a change in the level of income of the population, the level of poverty.

Using the graph method, a 10-level structure of the interdependencies of fiscal indicators and indicators of macroeconomic development in Azerbaijan has been determined (Figure 1). The first 2 levels are formed with fiscal policy indicators, while levels 3 to 10 contain indicators of macroeconomic development, which were most sensitive to changes in fiscal policy parameters.

According to the analysis results, the 1 st level of the hierarchy formed indicators that characterize the dynamics and structure of state budget expenditures: that is, the state budget expenditures growth ratio (Ex.GR); the specific weight of productive expenditures in the structure of state budget expenditures (ExEC); the specific weight of expenditures on social protection and social security (ECOSOC) on education (ExED), on health care $(\mathrm{ExH})$, for culture (ExC), for science (ECSC), for the judiciary, law enforcement agencies and the prosecutor's office (ExJ), for the provision of legislative and executive power, local governments (ExLEG). The lower level of the hierarchy of these indicators is explained by the fact that the volume of government spending directly affects the budget balance and 
government debt as a source of financing the negative balance in the current period. The structure of expenditures on budget revenues was manifested without a time lag and with a time lag of 1-2 years. All considered, time lags showed a statistically significant causal relationship between the structure of expenditures and the state budget revenue growth ratio (Rev.GR).

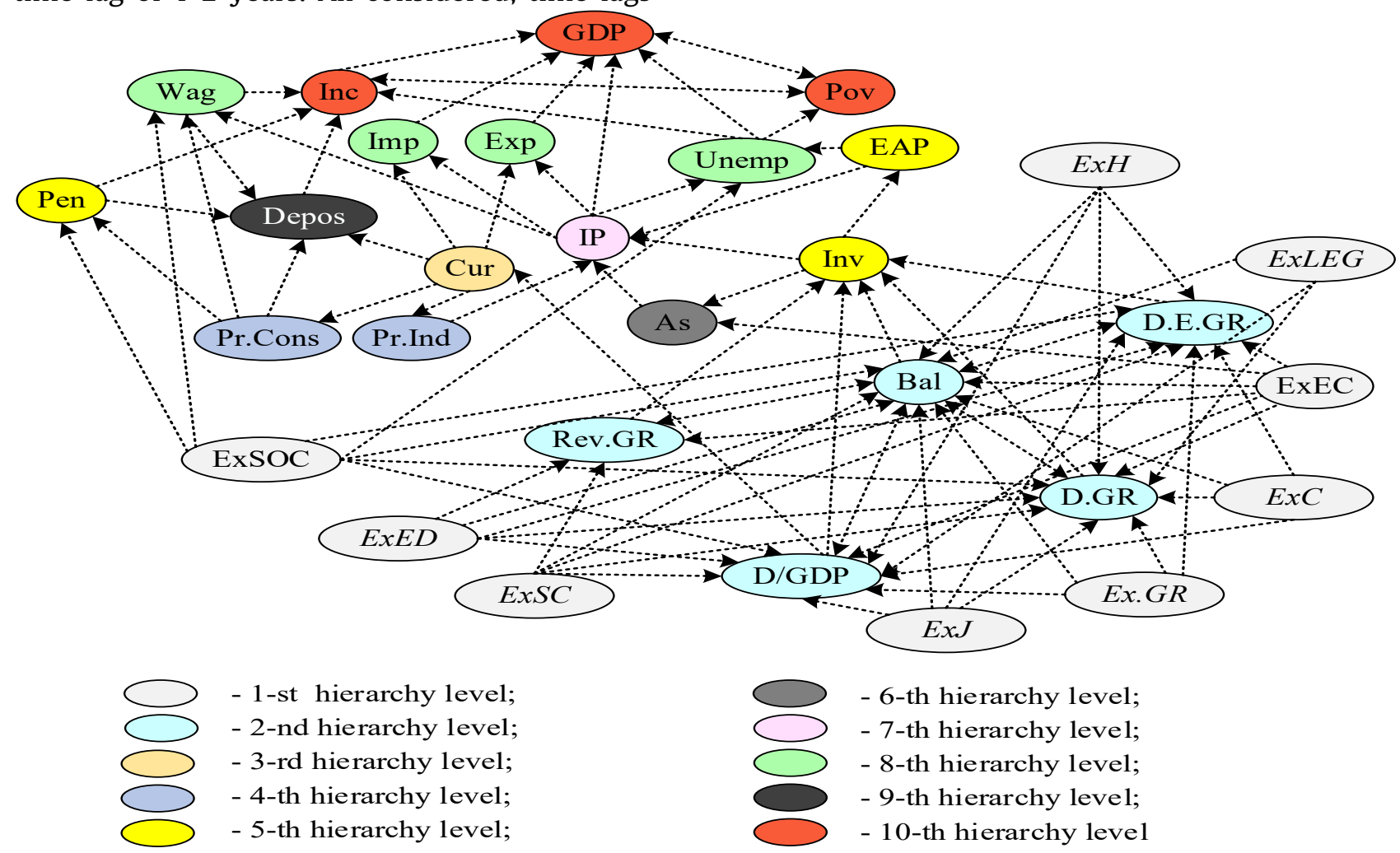

Figure 1: Graph of causal relationships between indicators of the fiscal policy effectiveness of and indicators of economic development in Azerbaijan

Such fiscal indicators form the second level of the hierarchy as the government debt growth index, the government budget revenue growth ratio, the ratio of the budget balance to GDP, the percentage of government debt to GDP, and the ratio of external government debt to GDP. This hierarchy level is characterized by indicators of fiscal risks caused by the structure of state budget expenditures. The resulting influence of fiscal risks on macroeconomic development was reflected through changes in GDP per capita, the index of growth in income of the population, and the level of poverty, reflecting the highest level of the hierarchy - the 10th level.

The use of factor analysis by the method of principal components made it possible to determine the parameters of the integral model of macroeconomic development:
$I=0.371 \times G D P^{\prime}+0.330 \times P o v^{\prime}+0.299 \times I n c^{\prime}$,

Where:

\section{$I$ - integral indicator of economic} development;

GDP', Pov', Inc'- normalized values of indicators.

The adequacy of the factor analysis is evidenced by the cumulative variance indicator of $87.3 \%$ with a sufficient $80 \%$. GDP, Inc indicators are stimulants in assessing macroeconomic development; their growth is evidence of the country's development with Pov - a destimulator (formula 4).

In addition to the financial indicators that influence macroeconomic development, identified by the results of the constructed graph 
(Figure 1), the models were supplemented with an exogenous indicator - the index of world oil prices. This is because $36 \%-42 \%$ of the country's GDP during 2017-2019 was due to the oil and gas sector, and the downward dynamics of the GDP indicator in 2020 was due to a $32 \%$ decrease in revenues of the oil and gas sector (The State Statistical Committee of the Republic of Azerbaijan, 2021). The decline in world oil prices for oil-exporting countries has had the greatest destabilizing effect on economic development during the COVID-19 pandemic (Jin \& Xiong, 2021; Yasmin, El Refae \& Eletter, 2020). Thus, the independent variables of the constructed models were indicators of the dynamics and structure of state budget expenditures, the growth index of world oil prices (P), and indicators of fiscal risks. To ensure the commensurability of the indicators, their normalized values were used, and for the indicators of the structure of expenses, the specific weight, expressed in shares.

The statistically significant F-test and t-test regression models are shown in Table 1.

Table 1: Influence models of fiscal indicators on the macroeconomic development of Azerbaijan

\begin{tabular}{|c|c|c|}
\hline Mathematical model & $\begin{array}{l}\text { F-test } \\
\text { value }\end{array}$ & t-test value \\
\hline \multicolumn{3}{|c|}{ Influence models without time lag } \\
\hline $\begin{array}{l}B a I=2.27 \times E X E C-0.06 \times E X S O C-0.01 \times E X E D \\
-1.84 \times E X H-2.33 \times E X C-0.03 \times E X S C- \\
2.48 \times E X J-2.36 \times E X L E G-0.13 \times E X . G R+1.15 \times P \\
-0.16\end{array}$ & 21.48 & $\begin{array}{l}\mathrm{t}(E x E C)=3.08 ; \mathrm{t}(E x S O C)=-2.37 ; \\
\mathrm{t}(E x E D)=-2.68 ; \mathrm{t}(E x H)=-3.04 ; \mathrm{t}(E x C)=- \\
2.77 ; \mathrm{t}(E x S C)=-2.38 ; \mathrm{t}(E x /)=-3.18 ; \\
\mathrm{t}(E x L E G)=-2.86 ; \mathrm{t}(E x . G R)=-2.94 ; \\
\mathrm{t}(P)=2.88\end{array}$ \\
\hline $\operatorname{Rev} . G R=1.04 \times E x E C+0.18 \times P-0.33$ & 39.84 & $\mathrm{t}(E X E C)=4.08 ; \mathrm{t}(P)=3.11$ \\
\hline $\begin{array}{l}D / G D P=-0.11 \times E X E C-0.18 \times \\
E X S O C+1.35 \times E \times E D+1.41 \times E x H+1.37 \times E X C+ \\
1.30 \times E X S C+2.47 \times E X J+2.43 \times E X L E G \\
+1.14 \times E X . G R-0.30 \times P+0.03\end{array}$ & 36.85 & $\begin{array}{l}\mathrm{t}\left(E_{X} E C\right)=-2.54 ; \mathrm{t}\left(E_{X} S O C\right)=-2.82 ; \\
\mathrm{t}\left(E_{X} E D\right)=2.33 ; \mathrm{t}\left(E_{X} H\right)=3.18 \\
\mathrm{t}\left(E_{X} C\right)=3.07 ; \mathrm{t}\left(E_{X} S C\right)=3.11 ; \\
\mathrm{t}\left(E_{X}\right)=2.73 ; \mathrm{t}\left(E_{X} L E G\right)=2.11 \\
\mathrm{t}\left(E_{X} . G R\right)=2.39 ; \mathrm{t}(P)=-3.15\end{array}$ \\
\hline $\begin{array}{l}D . G R=-0.67 \times E \times E C+ \\
0.02 \times E X S O C+0.98 \times E X E D+1.29 \times E x H+ \\
1.51 \times E x C+0.94 \times E X S C+3.06 \times E x J+2.22 \\
\times E X L E G+0.43 \times E x . G R-0.50 \times P+0.23\end{array}$ & 44.12 & $\begin{array}{l}\mathrm{t}(E X E C)=-2.90 ; \mathrm{t}(E X S O C)=2.73 \\
\mathrm{t}(E X E D)=2.81 ; \mathrm{t}(E X H)=2.95 \\
\mathrm{t}(E X C)=2.96 ; \mathrm{t}(E X S C)=3.38 \\
\mathrm{t}\left(E_{X}\right)=3.94 ; \mathrm{t}\left(E_{X} L E G\right)=3.51 \\
\mathrm{t}\left(E_{X} . G R\right)=2.96 ; \mathrm{t}(P)=-2.99\end{array}$ \\
\hline $\begin{array}{l}D . E / G D P=-0.18 \times E x E C- \\
0.10 \times E X S O C+1.10 \times E X E D+ \\
1.28 \times E x H+2.17 \times E x C+1.09 \times E x S C+2.51 \times E X J+ \\
2.50 \times E x L E G+1.27 \times E x . G R-0.30 \times P-0.01\end{array}$ & 29.04 & $\begin{array}{l}\mathrm{t}(E X E C)=-2.44 ; \mathrm{t}(E X S O C)=2.91 \\
\mathrm{t}(E x E D)=2.53 ; \mathrm{t}(E X H)=3.29 \\
\mathrm{t}(E x C)=2.34 ; \mathrm{t}\left(E_{X} S C\right)=2.55 \\
\mathrm{t}(E X)=3.09 ; \mathrm{t}(E X L E G)=3.01 \\
\mathrm{t}\left(E_{X} . G R\right)=3.11 ; \mathrm{t}(P)=-3.38\end{array}$ \\
\hline 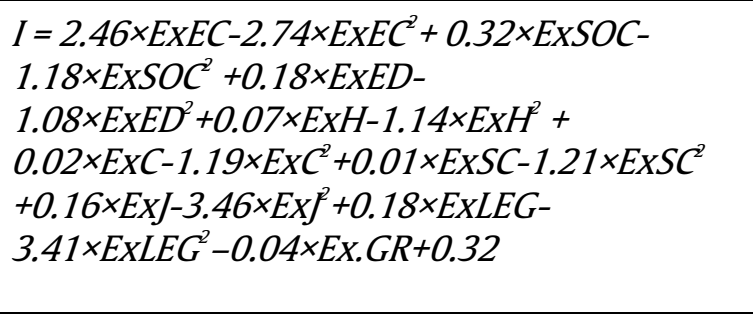 & 49.01 & 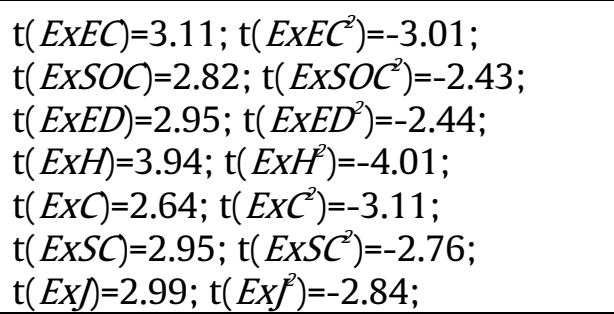 \\
\hline
\end{tabular}


Table 1: Continued

\begin{tabular}{|c|c|c|}
\hline & & $\begin{array}{l}\mathrm{t}(E X L E G)=2.76 ; \mathrm{t}\left(E X L E G^{2}\right)=-2.38 \\
\mathrm{t}(E X . G R)=2.94\end{array}$ \\
\hline $\begin{array}{l}I=0.36 \times B a I+0.82 \times R e v . G R-0.39 \times D / G D P- \\
0.02 \times D . G R-0.59 \times D . E / G D P+0.63\end{array}$ & 22.14 & $\begin{array}{l}\mathrm{t}(B a /)=2.84 ; \mathrm{t}(\text { Rev.GR })=2.38 ; \\
\mathrm{t}(D / G D P)=-3.01 ; \mathrm{t}(D . G R)=-3.11 ; \mathrm{t}(D . E \\
/ G D P)=-2.86\end{array}$ \\
\hline \multicolumn{3}{|c|}{ Influence Models with Time Lag } \\
\hline $\begin{array}{l}B a l=2.81 \times E \times E C-0.78 \times E \times S O C(-1) \\
+0.07 \times E \times E D(-2)-0.71 \times E x H- \\
3.14 \times E x C+0.21 \times E \times S C(-2)-8.85 \times E x J- \\
5.44 \times E \times L E G-0.11 \times E x . G R+1.01 \times P\end{array}$ & 34.18 & $\begin{array}{l}\mathrm{t}(E X E C)=3.11 ; \mathrm{t}(E X S O C)=-2.56 ; \\
\mathrm{t}(E x E D)=3.05 ; \mathrm{t}(E x H)=-3.37 ; \mathrm{t}(E x C)=- \\
2.94 ; \mathrm{t}(E x S C)=3.03 ; \mathrm{t}(E x /)=-3.68 ; \\
\mathrm{t}(E x L E G)=-3.17 ; \mathrm{t}(E x . G R)=-3.04 ; \\
\mathrm{t}(P)=3.48\end{array}$ \\
\hline $\begin{array}{l}\text { Rev.GR }=9.68 \times E \times E C+0.06 \times E \times E D(-2) \\
+0.09 \times E x S C(-2)+0.21 \times P-0.11\end{array}$ & 22.86 & $\begin{array}{l}\mathrm{t}(E X E C)=3.33 ; \mathrm{t}(E X E D)=2.94 \\
\mathrm{t}(E X S C)=3.09 ; \mathrm{t}(P)=3.15\end{array}$ \\
\hline $\begin{array}{l}D / G D P=-0.37 \times E \times E C+0.47 \times E \times S O C(-1)- \\
0.04 \times E x E D(-2)+0.68 \times E x H+0.88 \times E x C- \\
0.19 \times E X S C(-2)+1.50 \times E x J+ \\
1.32 \times E X L E G+0.11 \times E x . G R-0.90 \times P+1.68\end{array}$ & 37.46 & $\begin{array}{l}\mathrm{t}(E X E C)=-2.99 ; \mathrm{t}\left(E_{X} S O C\right)=3.11 ; \\
\mathrm{t}\left(E_{X} E D\right)=-2.64 ; \mathrm{t}(E X H)=3.00 ; \\
\mathrm{t}\left(E_{X} C\right)=3.57 ; \mathrm{t}\left(E_{X} S C\right)=-2.91 ; \\
\mathrm{t}\left(E_{X}\right)=4.01 ; \mathrm{t}\left(E_{X} L E G\right)=2.90 \\
\mathrm{t}\left(E_{X} . G R\right)=2.88 ; \mathrm{t}(P)=-3.64\end{array}$ \\
\hline $\begin{array}{l}D . G R=-0.54 \times E \times E C+0.44 \times E \times S O C(-1)- \\
0.08 \times E \times E D(-2)+0.67 \times E \times H+0.96 \times E x C- \\
0.15 \times E x S C(-2)+1.42 \times E x J+ \\
0.97 \times E x L E G+0.17 \times E x . G R-1.00 \times P+1.72\end{array}$ & 51.39 & $\begin{array}{l}\mathrm{t}(E X E C)=-2.53 ; \mathrm{t}(E X S O C)=2.38 \\
\mathrm{t}(E x E D)=-2.66 ; \mathrm{t}(E X H)=2.41 ; \\
\mathrm{t}(E x C)=3.15 ; \mathrm{t}(E X S C)=-3.04 ; \\
\mathrm{t}(E x /)=3.11 ; \mathrm{t}(E X L E G)=3.01 \\
\mathrm{t}(E X . G R)=2.88 ; \mathrm{t}(P)=-2.71\end{array}$ \\
\hline $\begin{array}{l}D . E / G D P=-0.29 \times E \times E C+0.53 \times E X S O C(-1)- \\
0.06 \times E \times E D(-2)+0.85 \times E \times H+1.28 \times E X C- \\
0.23 \times E X S C(-2)+1.98 \times E X J+1.58 \times E x L E G \\
+0.15 \times E x . G R-0.90 \times P+1.72\end{array}$ & 46.27 & $\begin{array}{l}\mathrm{t}(E X E C)=-2.94 ; \mathrm{t}(E X S O C)=4.01 \\
\mathrm{t}(E X E D)=-3.11 ; \mathrm{t}(E X H)=3.85 \\
\mathrm{t}(E X C)=2.90 ; \mathrm{t}(E X S C)=-3.15 \\
\mathrm{t}(E X /)=3.69 ; \mathrm{t}(E X L E G)=3.71 \\
\mathrm{t}(E X . G R)=3.08 ; \mathrm{t}(P)=-3.54\end{array}$ \\
\hline $\begin{array}{l}I=1.16 \times E X E C-1.24 \times E X E C^{2}+0.08 \times E X S O C(-1)- \\
0.32 \times E X S O C(-1)^{2}+0.03 \times E X E D(-2)- \\
0.12 \times E X E D(-2)^{2}+0.002 \times E X H-0.02 \times E X H^{2}+ \\
0.002 \times E X C-0.08 \times E x C^{2}+0.01 \times E X S C(-2)- \\
0.15 \times E X S C(-2)^{2}+0.01 \times E X J- \\
0.34 \times E X J^{2}+0.01 \times E X L E G-0.25 \times E X L E G^{2}- \\
0.18 \times E X . G R+0.08\end{array}$ & 30.08 & $\begin{array}{l}\mathrm{t}(E X E C)=3.86 ; \mathrm{t}\left(E X E C^{2}\right)=-2.81 ; \\
\mathrm{t}(E X S O C)=3.14 ; \mathrm{t}\left(E X S O C^{2}\right)=-2.99 ; \\
\mathrm{t}(E X E D)=2.71 ; \mathrm{t}\left(E X E D^{2}\right)=-3.01 ; \\
\mathrm{t}(E X H)=3.50 ; \mathrm{t}\left(E X H^{2}\right)=-3.46 ; \\
\mathrm{t}(E X C)=4.64 ; \mathrm{t}\left(E X C^{2}\right)=-2.84 ; \\
\mathrm{t}(E X S C)=2.67 ; \mathrm{t}\left(E X S C^{2}\right)=-2.58 \\
\mathrm{t}(E X)=3.11 ; \mathrm{t}\left(E X F^{2}\right)=-2.90 ; \\
\mathrm{t}(E X L E G)=2.84 ; \mathrm{t}\left(E X L E G^{2}\right)=-3.29 ; \\
\mathrm{t}(E X . G R)=4.01\end{array}$ \\
\hline $\begin{array}{l}I=1.31 \times B a I+0.43 \times R e v . G R-0.05 \times D / G D P- \\
0.03 \times D . G R-0.01 \times D . E / G D P\end{array}$ & 39.61 & $\begin{array}{l}\mathrm{t}(B a I)=3.11 ; \mathrm{t}(\text { Rev.GR })=2.97 \\
\mathrm{t}(D / G D P)=-3.50 ; \mathrm{t}(D . G R)=-4.01 ; \mathrm{t}(D . E \\
/ G D P)=-3.00\end{array}$ \\
\hline
\end{tabular}

Since the time range of the study included 2020 , which was characterized by the spread of COVID-19 throughout the world, the constructed models (Table 1) were tested for structural breaks using the Chow test. The value of the indicator Prob $=0.68$ (exceeding 0.05) indicates the absence of structural changes. Despite the crisis conditions, the nature of the relationship between the indicators, with a probability of error $\mathrm{p}=0.05$, was identical during 1991-2020. 
The constructed models testified to the statistically significant influence of indicators of the dynamics and structure of expenditures of the state budget of Azerbaijan on other fiscal indicators, such as the ratio of the balance of the state budget to GDP, the growth index of state budget revenues, the proportion of public debt to GDP, the percentage of external debt to GDP, and the growth index of public debt, and on the integral indicator of macroeconomic development. The impact is significant in the current period (no time lag) as well as a time lag of 1-2 years.

Changes in macroeconomic development indicators under the influence of government spending dynamics in Azerbaijan for 2020 are shown in Table. 2.

Table 2: Changes in macroeconomic development indicators during the influence of changes of dynamics and structure of budget expenditures in Azerbaijan for 2020

\begin{tabular}{|c|c|c|c|c|c|c|c|c|c|c|}
\hline & ExEC & ExSOC & ExED & ExH & ExC & ExSC & ExJ & ExLEG & Ex.GR & Total \\
\hline \multicolumn{11}{|c|}{ Change in indicators during the current period (without time lag),\% } \\
\hline Bal & $-4.7 \%$ & $-0.3 \%$ & $0.0 \%$ & $-11.4 \%$ & $0.1 \%$ & $0.0 \%$ & $-4.0 \%$ & $-1.7 \%$ & $-6.3 \%$ & $-28.4 \%$ \\
\hline Rev.GR & $-9.8 \%$ & & & & & & & & & $-9.8 \%$ \\
\hline$D / G D P$ & $0.0 \%$ & $-0.1 \%$ & $0.7 \%$ & $1.3 \%$ & $0.0 \%$ & $0.0 \%$ & $0.6 \%$ & $0.3 \%$ & $8.1 \%$ & $10.7 \%$ \\
\hline$D . E / G D P$ & $0.1 \%$ & $-0.1 \%$ & $0.6 \%$ & $1.2 \%$ & $0.0 \%$ & $0.0 \%$ & $0.6 \%$ & $0.3 \%$ & $9.3 \%$ & $11.9 \%$ \\
\hline$D . G R$ & $0.5 \%$ & $0.0 \%$ & $1.1 \%$ & $2.8 \%$ & $0.0 \%$ & $0.0 \%$ & $1.7 \%$ & $0.6 \%$ & $7.3 \%$ & $14.0 \%$ \\
\hline $\begin{array}{l}I \text { (direct } \\
\text { influence) }\end{array}$ & $-8.3 \%$ & $2.3 \%$ & $-0.6 \%$ & $-1.5 \%$ & $0.0 \%$ & $0.0 \%$ & $-2.7 \%$ & $-0.2 \%$ & $-11.1 \%$ & $-22.1 \%$ \\
\hline $\begin{array}{l}I \text { (influence } \\
\text { through } \\
\text { indicators of } \\
\text { fiscal risks) }\end{array}$ & $-8.1 \%$ & $1.9 \%$ & $-0.5 \%$ & $-1.8 \%$ & $0.0 \%$ & $0.0 \%$ & $-2.4 \%$ & $-0.1 \%$ & $-10.4 \%$ & $-21.4 \%$ \\
\hline \multicolumn{11}{|c|}{ Change in indicators in over 2 years ${ }^{*}, \%$} \\
\hline Bal & $-2.7 \%$ & $-2.0 \%$ & $0.1 \%$ & $-2.1 \%$ & $0.1 \%$ & $0.0 \%$ & $-6.7 \%$ & $-1.9 \%$ & $-2.5 \%$ & $-17.7 \%$ \\
\hline Rev.GR & $-2.8 \%$ & & $0.0 \%$ & & & $0.0 \%$ & & & & $-2.8 \%$ \\
\hline$D / G D P$ & $0.4 \%$ & $1.2 \%$ & $-0.1 \%$ & $1.9 \%$ & $0.0 \%$ & $0.0 \%$ & $1.1 \%$ & $0.4 \%$ & $2.5 \%$ & $7.5 \%$ \\
\hline$D . E / G D P$ & $0.3 \%$ & $1.2 \%$ & $-0.1 \%$ & $2.2 \%$ & $0.0 \%$ & $0.0 \%$ & $1.4 \%$ & $0.5 \%$ & $3.1 \%$ & $8.5 \%$ \\
\hline$D . G R$ & $0.6 \%$ & $1.3 \%$ & $-0.1 \%$ & $2.3 \%$ & $0.0 \%$ & $0.0 \%$ & $1.3 \%$ & $0.4 \%$ & $4.5 \%$ & $10.1 \%$ \\
\hline $\begin{array}{l}I \text { (direct } \\
\text { influence) }\end{array}$ & $-4.2 \%$ & $-1.9 \%$ & $-0.4 \%$ & $-2.8 \%$ & $0.0 \%$ & $0.0 \%$ & $-2.6 \%$ & $-0.9 \%$ & $-3.4 \%$ & $-16.2 \%$ \\
\hline $\begin{array}{l}I \text { (influence } \\
\text { through } \\
\text { indicators of } \\
\text { fiscal risks) }\end{array}$ & -4.0 & -1.6 & -0.5 & -2.6 & 0.0 & 0.0 & -2.1 & -0.7 & -3.3 & -14.8 \\
\hline
\end{tabular}

* calculated changes of macroeconomic development indicators in 2 years to take into account the reaction to all independent variables of the constructed regression models, some of which have a time lag of 2 years.

The adequacy of the constructed models as evidenced by the F-criterion and t-criterion, the

empirical values of which (shown in Table 1 ), in modulus, exceed the tabular values 2.48-3.35 for 
the F-criterion and 2.05-2.18 for the t-criterion at a significance level of $\mathrm{p}=0.05$.

The results show that an increase in state budget expenditures with their current structure hurts macroeconomic development in the current period and the future (over 2 years) since it causes the generation of fiscal risks in the national economy. The influence of the indicated fiscal risks causes a decrease in the integral indicator of Azerbaijan's macroeconomic development by $10.4 \%-11.1 \%$ in the current period and $3.4 \%-3.9 \%$ in the future.

Changes in the structure of public spending in Azerbaijan during the COVID-19 pandemic are related to the greatest increase in the share of spending on education (by 1.5 percentage points), on health care (by 2.8 percentage points), on social protection and social security (by 2.4 percentage points), the judiciary, law enforcement agencies, and the prosecutor's office (by 0.7 percentage points) and a reduction in part of economic costs (by 0.9 percentage points). These changes in the structure of expenses lead to the intensification of the following fiscal risks:

1) a decrease in state budget revenues - a decrease in non-production costs (power clauses) leads to a decrease in state budget revenues by $9.8 \%$ in the current period (in 2020 ) and by $2.8 \%$ in 2 years (in 2022);

2) taking into account that the indicator of the budget balance to GDP ratio in 2019 was $8.1 \%$, changes in the structure and dynamics of expenditures (without the influence of other indicators) would lead to a budget deficit in the current period (the value of the actual indicator is $-1.37 \%)$. In the long term, the indicator of budget balance to GDP ratio will be - $0.64 \%$;

3 ) growth of public debt by $14 \%$ in the current period and $10.1 \%$ in 2 years;

4) growth of the ratio of public debt to GDP by $10.7 \%$ in the current period and $7.5 \%$ in 2 years;

5) a ratio of external debt to GDP of $11.9 \%$ in the current period and $8.5 \%$ in 2 years.

Among the indicators of the structure of expenditures, the most significant destabilizing effect on economic development was a decrease in economic expenditures in the structure of state budget expenditures (a decrease in the integral indicator by $8.1 \%-8.3 \%$ in the current period and $4 \%-4.2 \%$ in the future), an increase in integral indicator by $1.5 \%-1.8 \%$ in the current period and $2.6 \%-2.8 \%$ in the future), an increase in the part of the costs of the judiciary, law enforcement agencies and the prosecutor's office (decrease in the integral indicator by $2.4 \%-2.7 \%$ in the current period and $2.1 \%-2.6 \%$ in the future). A positive impact on macroeconomic development in 2020 was exerted by an increase in the specific weight of the expenditures on social protection and social security by increasing the population's income and stimulating total expenditures. But this positive effect in the current period is leveled in a longer period (over 2 years).

The total decrease in the integral indicator of macroeconomic development due to fiscal measures taken during the pandemic will amount to $21.4 \%-22.1 \%$ in the current period, $14.8 \%-16.2 \%$ in the future.

By finding the derived functions of the dependence of the integral indicator of macroeconomic development on the dynamics and structure of budget expenditures, the optimal structure of state budget expenditures was determined, which can neutralize the negative impact of fiscal risks in the context of the COVID19 pandemic and its further consequences in the short term. Optimization of the structure of budgetary expenditures in Azerbaijan implies an increase in production costs by $15.2 \%$ compared to the base period of 2020, as well as expenditures on education by $0.4 \%$, science by $1.6 \%$, an an increase in expenditures on social protection and security by $0.6 \%$ also is expected. At the same time, power clauses should be reduced by almost $18 \%$.

\section{DISCUSSION}

This empirical approach used in our study made it possible to reliably substantiate the directly proportional relationship between the dynamics of government spending and the level of fiscal risks and their destructive multiplicative impact on the economic state of the country, provided that the current level of revenues of the state budget of the country remains unchanged. Provided that the same level of expenditures remains and unproductive items of budget expenditures increase, the level of fiscal risks and 
their destructive impact on the national economy's development will only worsen. However, the real test for Azerbaijan lies ahead. As a result of the constant violation of the requirements of the "Long-term strategy for the management of oil and gas revenues for the period 2005-2025" and more than 90\% of transfers to the state budget from the country's oil and gas revenues, the revenues of the State Oil Fund since 2003 were mainly used for current consumption (Zotin, 2017). But according to official estimates of experts, due to the exhaustion of oil fields in Azerbaijan, oil production may fall by more than half by 2025 . This can decrease inequality in the country, as oil revenues have positive impacts on inequality. According to Gulaliyev et. al (2018), the level of inequality is very high while the role of fiscal policy for the redistribution of income is not high.

The study results make it possible to assert that today the effectiveness of fiscal policy in Azerbaijan is extremely low in supporting and confronting the challenges of the national economy that were provoked by the spread of the COVID19 pandemic. This is manifested somewhat in the strengthening of such fiscal risks during the pandemic as a decrease in the level of the ratio of the state budget balance to GDP, an increase in the level of public debt, an increase in the state budget deficit, and an increase in the level of the ratio of debt (aggregate and external) to GDP. And in maintaining their destructive influence on the development of the economy and reducing its positive dynamics in the next two years. An increase in budget expenditures while maintaining their existing structure will not only not contribute to the development of the country's economy but will negatively affect its dynamics. This confirms the scientific hypothesis that there are optimal indicators of the level of budget expenditures and their structure for the conditions for implementing fiscal policy in each specific country (Bouakez, Guillard \& RoulleauPasdeloup, 2020).

Within the framework of the study, it is empirically substantiated that the effect of an additional unit of budget expenditures depends on its functional purpose: unproductive expenditures, in contrast to productive ones (investments in physical and human capital), are mainly for the final consumption of resources. Therefore, they have a smaller multiplier effect both for GDP and for the rate of its growth and neutralization of fiscal risks. Hence, the dependence of the rate of economic growth on the structure of the general government's budget arises. Therefore, the government of Azerbaijan should revise the anti-crisis strategy of fiscal policy as soon as possible. In the context of a deteriorating external economic situation, a decrease in budget expenditures can stabilize. However, from the perspective of neutralizing fiscal risks, it is optimal to reduce primarily unproductive costs while simultaneously increasing or at least not reducing productive ones.

\section{CONCLUSION}

The main scientific results of this study substantiated the ineffectiveness of fiscal policy. The optimal structure for state budget expenditures to increase the efficiency of fiscal policy should amount to at least $46.9 \%$ of production budget expenditures. Other proportions are: education costs $10.9 \%$; health care $4.2 \%$; social protection, and social security $12.4 \%$; culture $1.2 \%$; science $2.1 \%$; judicial authorities, law enforcement agencies, and prosecutors $1.1 \%$; provision of legislative and executive authorities, local government $1.9 \%$ and other expenses $19.3 \%$. This structuring of budget expenditures can ensure the impact of fiscal policy on the growth of the integral indicator of economic development by $45.1 \%$ compared to its value for 2020 with the same dynamics of expenditures and oil prices.

The results obtained are based on a sample of fiscal policy, fiscal risks, and economic development of one country - Azerbaijan. They therefore cannot apply to the assessment of fiscal risks and the effectiveness of public spending for the economic development of other countries.

\section{REFERENCES}

Ari, I., \& Koc, M. (2020). Economic Growth, Public and Private Investment: A Comparative Study of China and the United States. Sustainability, 12(6), 2243. doi.org/10.3390/su12062243. 
Bouakez, H., Guillard, M., \& Roulleau-Pasdeloup, J. (2020). The optimal composition of public spending in a deep recession. Journal of Monetary Economics, 114, 334-349. doi.org/10.1016/j.jmoneco.2019.03.006.

Brown, T.R. (2019). World War II in America: Spending, deficits, multipliers, and sacrifice. https://voxeu.org/article/world-war-iiamerica-spending-deficits-multipliers-andsacrifice

Divino, J.A., Maciel, D.T.G.N., \& Sosa, W. (2017). Optimal Composition of the Public Spending and Economic Growth. http://mesp.unb.br/images/eventofederalis mo/trabalhos/Paper-D-M-S-JED.pdf

Edelberg, W., \& Sheiner, L. (2020). What could additional fiscal policy do for the economy in the next three years? The Brookings Institution. https://www.brookings.edu/research/whatcould-additional-fiscal-policy-do-for-theeconomy-in-the-next-three-years/

Gulaliyev, M., Ismayilzade, A., Azizov, A., Kazimov, F., \& Mir-Babayev, R. (2018). Assessing the degree of inequality in the distribution of national income and its macroeconomic consequences in Azerbaijan. Amazonia-investiga, 7, 17, 85108.

Gross, T. (2020). Dynamic optimal fiscal policy in a transfer union. Review of Economic Dynamics. doi.org/10.1016/j.red.2020.10.010.

Hu, X., \& Lei, L. (2017). The Local Government's Fiscal Risks and Their Solutions under Supply-Side Reform in China. Proceedings of the 2017 International Conference on Education Science and Economic Management. doi.org/10.2991/icesem17.2017.1.

International Monetary Fund. (2016). Analyzing and managing fiscal risks - best practices. Washington, D.C.

International Monetary Fund. (2021). Policy responses to Covid-19. https://www.imf.org/en/Topics/imf-andcovid19/Policy-Responses-to-COVID-19

Jin, H., \& Xiong, C. (2021). Fiscal stress and monetary policy stance in oil-exporting countries. Journal of International Money and Finance, 111, 102302. doi.org/10.1016/j.jimonfin.2020.102302.

Knoema. (2021). World Data Atlas. Retrieved April 27, 2021, from https://knoema.ru/atlas

Larch, M. Orseau, E., \& van der Wielen, W. (2021). Do EU fiscal rules support or hinder counter-cyclical fiscal policy? Journal of International Money and Finance, 112, 102328.

doi.org/10.1016/j.jimonfin.2020.102328.

Makin, A.J., \& Layton, A. (2021). The global fiscal response to COVID-19: Risks and repercussions. Economic Analysis and Policy, 69, 340-349. doi.org/10.1016/j.eap.2020.12.016.

Malcolm, X. (2017). Investigating the Optimal Level of Government Spending to Maximize Economic Growth in Jamaica. Bank of Jamaica. https://certnet.com/files/publications/conference/2017/ XavierMalcolmInvestigatingtheOptimalLeve lofGovernmentSpendingtoMaximizeEconom icGrowthinJamaica.pdf.

Megits, N., Neskorodieva, I., \& Schuster, J. (2020). Impact assessment of the COVID19 on trade between Eastern Europe and China. Journal of Eastern European and Central Asian Research, 73), 385-399. doi.org/10.15549/jeecar.v7i3.579.

Ministry of Finance Republic of Azerbaijan. (2021). Analysis of the execution of budget incomes and expenses. Retrieved April 27, 2021, from http://www.maliyye.gov.az/en/static/15/ana lysis-of-the-execution-of-budget-incomesand-expenses

Montes, G.C., \& de Hollanda Lima, N.T. (2021). Discretionary fiscal policy, fiscal credibility and inflation risk premium. The Quarterly Review of Economics and Finance. doi.org/10.1016/j.qref.2021.01.006

OECD. (2020a). COVID-19 crisis response in Eastern Partner countries. https://www.oecd.org/coronavirus/policyresponses/covid-19-crisis-response-in-eueastern-partner-countries-7759afa3/

OECD. (2020b). Best Practices for Managing Fiscal Risks. https://www.oecd.org/officialdocuments/pu 
blicdisplaydocumentpdf $/$ cote $=$ GOV $/$ PGC/SB

$\mathrm{O}(2020) 6$ \&docLanguage $=\mathrm{En}$

Report. (2021). Capital of $\$ 4.5$ billion has been withdrawn from Azerbaijan.

https://report.az/ru/finansy/iz-

azerbajdzhana-vyveden-kapital-na-4-5mlrd-dollarov/

Soreg, K., \& Bermudez-Gonzalez, G. (2021). Measuring the Socioeconomic Development of Selected Balkan Countries and Hungary: A Comparative Analysis for Sustainable Growth. Sustainability, 13(2), 736. doi.org/10.3390/su13020736.

The Ministry of Energy of the Republic of Azerbaijan. (2020). The Organisation of Petroleum Exporting Countries (OPEC). https://minenergy.gov.az/en/beynelxalqteskilatlarla-elaqeler/neft-ixrac-edenolkeler-teskilati-opec-ile-emekdasliq

The State Statistical Committee of the Republic of Azerbaijan. (2021). Retrieved April 27, 2021, from https://www.stat.gov.az/?lang=en

United Nations. (2015). World Economic Situation and Prospects 2015. https://www.un.org/en/development/desa/p olicy/wesp/wesp_archive/2015wesp_chap1. pdf

Vinhado, F.D.S., \& Divino, J.A. (2019). Interactions between monetary and macroprudential policies in the transmission of discretionary shocks. The North American Journal of Economics and Finance, 50, 101020. doi.org/10.1016/j.najef.2019.101020.

Wakeman-Linn, J., Aturupane, C., Danninger, S., Gvenetadze, K., Hobdari, N., \& Le Borgne, E. (2004). Managing Oil Wealth: The Case of Azerbaijan. https://www.imf.org/external/pubs/nft/200 4/aze/oil/

Yasmin, T., El Refae, G. A., \& Eletter, S. (2020). Oil price and urgency towards economic diversification through effective reforms and policies in Caspian Basin. Journal of Eastern European and Central Asian Research, 73), 305-315. doi.org/10.15549/jeecar.v7i3.326.
Zotin, A. (2017). Azerbaijan: an oriental tale of 30 years.https://carnegie.ru/2017/03/24/rupub-68386

\section{ABOUT THE AUTHORS}

Shafa Guliyeva, email: shafa_guliyeva@unec.edu.az

Shafa Guliyeva, Doctor of sciences on economics, professor at Azerbaijan State University of Economics (UNEC), Baku, Azerbaijan

Nushaba Gadimli, PhD, associate professor of Mingachevir State University, Mingachevir, Azerbaijan

Yalchin Azizov, PhD, associate professor, the Institute of Economics of Azerbaijan National Academy of Sciences, Baku, Azerbaijan

Zaur Hajiyev, PhD, the Institute of Economics of Azerbaijan National Academy of Sciences, Baku, Azerbaijan

Sanan Bayramov, doctoral student of Azerbaijan State University of Economics (UNEC), Baku, Azerbaijan 